\title{
Strategies for Reducing Ruminant Methane Emissions
}

\author{
E. V. Sheida, S. A. Miroshnikov, G. K. Duskaev, K.N. Atlanderova and V.V. Grechkina \\ Federal Research Centre of Biological Systems and Agrotechnologies, RAS, Orenburg, Russia
}

\begin{abstract}
The paper studies the effect of additional administration of ultrafine particles on the cattle rumen microbiome composition. The in vitro method was used using the ANKOM Daisy II incubator according to a specialized method. Microflora analysis was performed using MiSeq (Illumina, USA) by a new generation sequencing method with a MiSeq reagent kit. After a detailed analysis of the structure and composition of the microbial community in the contents of the rumen sampled for different diets, it was found that no significant differences were observed in the bacterial communities, with the exception of a slight shift in the Bacteroidetes/Firmicutes ratio. However, we observed numerical differences in the abundance of some representatives, namely, with additional inclusion of $\mathrm{Fe}$ and $\mathrm{Cr} 2 \mathrm{O} 3$, decrease in the abundance of the methane-forming species Methanobrevibacter, Methanobacterium, Methanosphaera, and Methnaomicrobium was noted regarding the control.
\end{abstract}

\section{Introduction}

Methane production by ruminants is of global concern due to accumulation of greenhouse gases in the atmosphere, as well as the loss of energy consumed by animals [1]. Methane is produced in the rumen and cecum of animals by a group of archaea collectively known as methanogens, which are of the Euryarcheota type. The greatest production of methane is observed in ruminants, since methanogens are able to freely produce methane within the normal process of food digestion [2]. Ruminants can produce from 250 to 500 liters of methane per day [3]. Methane emissions from cattle are influenced by many factors, for example, feed intake, type of carbohydrate in the diet, feed processing, additional ingredients $[4,5]$. Manipulating these factors can reduce methane emissions. Digestion of food by microorganisms under anaerobic conditions leads to formation of acetate, propionate and butyrate, which are used by animals as an energy source, as well as for production of carbon dioxide $(\mathrm{CO} 2)$ and $\mathrm{CH} 4$, which are eliminated by belching [6]. All gases formed in the rumen within methanogenesis, in addition to their negative impact on the environment, contribute to the loss of $2-15 \%$ of the gross energy consumption [7] for the animal.

The feed composition or its quality affects the production of methane in ruminants. Digestion in the rumen depends on the activity of microorganisms, which require energy, nitrogen and minerals [8-10]. 
The aim of our study was to study the taxonomic composition of the rumen fluid with the additional inclusion of ultrafine preparations as a strategy for reducing formation of methane in the rumen.

\section{Materials and Methods}

\subsection{Object of the Study}

Ruminal fluid (CR), microbiome.

\subsection{Experiment Scheme}

The study of the rumen microbiome was performed on a model of bulls with a rumen fistula $(\mathrm{n}=3)$. The studies were carried out by the Latin square method.

The studies used ultradispersed ferrum particles obtained by the method of electric explosion of a conductor in an argon atmosphere (Advanced Powder Technologies, Tomsk). Ultrafine particles (UFP) Fe (d= $90 \mathrm{~nm}$, Z-potential $7.7 \pm 0.5 \mathrm{mV})$ contained $99.8 \%$ of $\mathrm{Fe}$. Before being included in the diet, ultrafine ferrum particles were dispersed in physiological solution using UZDN-2T (NPP Akadempribor, Russia) (35 kHz, $300 \mathrm{~W}$, $10 \mu \mathrm{A}, 30 \mathrm{~min})$, at a dose of $1.4 \mathrm{mg} / \mathrm{kg}$ feed; $\mathrm{Cr} 2 \mathrm{O} 3(\mathrm{~d}=91 \mathrm{~nm}$, specific surface area $9 \mathrm{~m} 2 / \mathrm{g}$, Z-potential $-93 \pm 0.53 \mathrm{mV}$ ), contained $99.8 \%$ of $\mathrm{Cr}$ was obtained by plasmachemical synthesis (Platina LLC, Moscow). Before being included in the diet, UFP was dispersed in physiological solution using an ultrasonic disperser UZDN-2 (NPP Akadempribor, Russia) $(35 \mathrm{kHz}, 300 \mathrm{~W}, 10 \mu \mathrm{A}, 30 \mathrm{~min})$, at a dose of $200 \mu \mathrm{g} / \mathrm{kg}$ of feed. Wheat bran was used as a control.

Investigations of the rumen microbiome were carried out by the in vitro method using the "artificial rumen" model using the device - ANKOM Daisy II incubator (modifications D200 and D200I) according to the specialized method. Distilled water was chosen as the dispersion medium.

In fistula animals, 3 hours after feeding, samples of rumen contents were taken, which were filtered through 4 layers of gauze and incubated in an artificial rumen at a constant $\mathrm{T}$ $=39^{\circ} \mathrm{C}$ for 24 hours. After incubation, the ruminal fluid was sampled with a syringe dispenser OPA-2-20 ecochem manufactured by Ekroskhim LLC, St. Petersburg, into Eppendorf microtubes with a volume of $1.5 \mathrm{ml}$. For analysis, we took $1.5 \mathrm{ml}$ of the substrate of the ruminal fluid, one sample for each sample. Keeping the animals and procedures within the experiments were in accordance with the instructions and recommendations of the Russian regulations (Order of the Ministry of Health of the USSR No. 755 dated August 12, 1977) and The Guide for Care and Use of Laboratory Animals (National Academy Press, Washington, D.C., 1996). Every effort has been made to minimize animal suffering and to reduce the number of samples used.

\subsection{Metagenomic Analysis of Rumen Microorganisms}

Microflora analysis was performed using MiSeq (Illumina, USA) by next generation sequencing (NGS) with MiSeq ${ }^{\circledR}$ Reagent Kit v3 (600 cycle). For bioinformatic processing of the results, the PEAR (Pair-End AssembeR, PEAR v0.9.8) program is used (Zhang J., Kobert K., Flouri T., Stamatakis A. PEAR: A fast and accurate Illumina Paired-End reAd merger. Bioinformatics, 2014, 30(5): 614-620 (doi: 10.1093/bioinformatics/btt593)). Filtration, de-replication, removal of chimeric sequences, clustering, sorting (cutting off singletons), removal of contamination is performed in the USEARCH program (usearch 
v8.0.1623_i86linux32, http://drive5.com/usearch). The fastq filter algorithm is used for filtering, derep prefix -for replication, cluster otus - for clustering and removal of chimeric sequences.

The sequencing results were processed using the Microsoft Excel 10 data analysis package, Microsoft Office software.

\subsection{Statistical Processing}

The numerical data were processed using the SPSS Statistics 20 software (IBM, USA), the mean $(\mathrm{M})$, standard deviations $( \pm \sigma)$, and standard deviation errors $( \pm \mathrm{SE})$ were calculated. To compare the options, a nonparametric method of analysis was used. Differences were considered statistically significant at $\mathrm{p} \leq 0.05$.

\section{Study Results}

Within the rumen microbiome, bacteria dominate and contribute most to the digestion and conversion of feed into VFA and microbial protein. The bacterial community of the rumen depends on the composition of the diet, types of feed, the age of the animals and the feeding strategy. Variations in these factors have a significant effect on rumen metabolism, which can affect both productivity and health of the animal.

Metagenomic sequencing the CR in the control group showed presence of 12 phyla, where 4 - dominant phyla, namely, the phylum Firmicutes - $17.28 \%$, Bacteroidetes $50.42 \%$, Verrucomicrobia - $13.13 \%$, Proteobacteria - $10.18 \%$. The dominant bacteria found in the control sample are presumably responsible for transformation of the main components of the diet - cellulose, hemicellulose, starch, organic acids, proteins (Figure 1). With introduction of ferrum UFP into the diet, there is a predominance of the number of acid-fast bacteria of the phylum of Bacteroidetes (55.61\%), Firmicutes $(16.26 \%)$, Verrucomicrobia $11.06 \%$, and Proteobacteria $9.27 \%$. Additional inclusion of UFP Cr2O3 contributed to increase in the number of representatives of the Bacteroidetes phylum relative to control by $10.07 \%$, Firmicutes - by $0.43 \%$, as well as decrease in Verrucomicrobia — by $4.8 \%$ and Proteobacteria - by $3.8 \%$. 

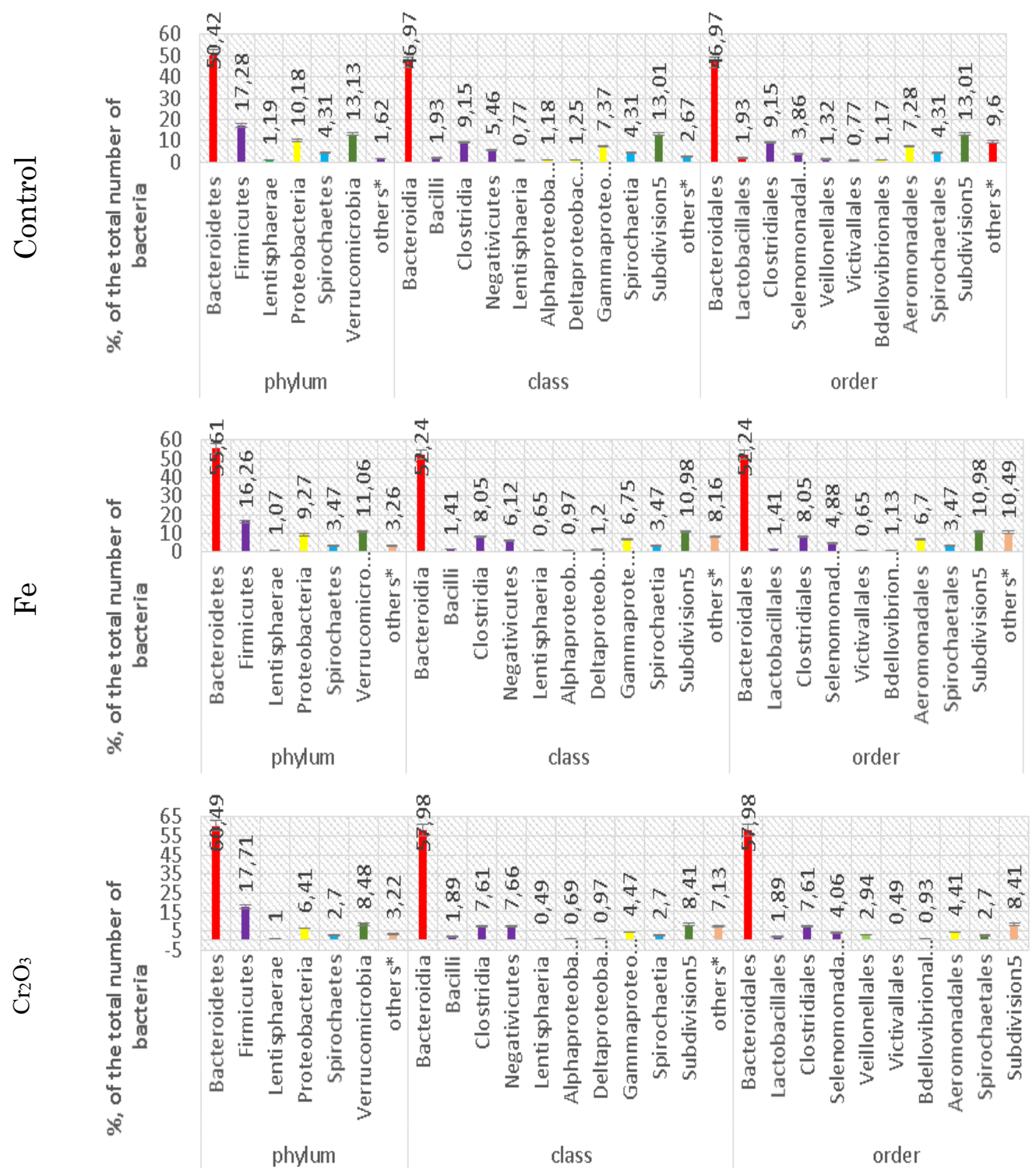

Other*: this group includes taxa, the number of which did not exceed $1.0 \%$ of the total number of bacteria

Fig. 1. Taxonomic groups of the rumen microbiome, $\%$ of the total number of bacteria in the sample.

In both the control and experimental groups, the predominance of the Bacteroidia, Clostridia and Negativicutes classes was noted, however, it shall be noted that the total number of bacteria in the control group was significantly higher than in the experimental groups.

The additional inclusion of UFP promoted an increase in the number of bacteria of the Prevotellaceae families by $3.6 \%(\mathrm{Fe})$ and $9.3 \%(\mathrm{Cr} 2 \mathrm{O} 3)$ relative to the control, as well as Selenomonadaceae, unclassified_Bacteroidales, and unclassified_Bacreria.

Also, in the study, when adding the UFP of ferrum and chromium, a decrease in the archaeal domain in the ruminal fluid was noted (Table 1). It was found, when ferrum and chromium UFP included, the number of representatives of the Methanobacteria methane- 
forming class decreased, the concentration in the group in presence of ferrum was lower by $11.6 \%$ relative to the control, and with introduction of chromium UFP - by $6.4 \%$ $(\mathrm{p} \leq 0.05)$. The number of representatives of the Methanomicrobia class in the experimental groups relative to the control also decreased significantly by $9.7 \%$ in presence of $\mathrm{Cr} 2 \mathrm{O} 3$ and by $2.8 \%$ in presence of $\mathrm{Fe}(\mathrm{p} \leq 0.01)$

Table 2. Taxonomic diversity of the Archaea domain of the rumen of cattle when using various additives in the diet, $\mathrm{n}=4$

\begin{tabular}{|c|c|c|c|c|}
\hline Group & class & order & family & genus \\
\hline \multirow[t]{4}{*}{ Control } & \multirow[t]{3}{*}{$\begin{array}{c}\text { Methanobacteria } \\
(9,02 \pm 0,77)\end{array}$} & \multirow[t]{3}{*}{$\begin{array}{c}\text { Methanobacteriales } \\
(9,02 \pm 0,77)\end{array}$} & \multirow[t]{3}{*}{$\begin{array}{c}\text { Methanobacteriaceae } \\
(9,02 \pm 0,77)\end{array}$} & $\begin{array}{l}\text { Methanobacterium } \\
\quad(0,11 \pm 0,07)\end{array}$ \\
\hline & & & & $\begin{array}{c}\text { Methanobrevibacter } \\
(8,69 \pm 0,80)\end{array}$ \\
\hline & & & & $\begin{array}{l}\text { Methanosphaera } \\
(0,21 \pm 0,08)\end{array}$ \\
\hline & $\begin{array}{c}\text { Methanomicrobia } \\
\left(0,72 \pm 0,10^{*}\right)\end{array}$ & $\begin{array}{c}\text { Methanomicrobiales } \\
(0,72 \pm 0,10)\end{array}$ & $\begin{array}{c}\text { Methanomicrobiaceae } \\
(0,72 \pm 0,10)\end{array}$ & $\begin{array}{c}\text { Methanomicrobium } \\
(0,72 \pm 0,10)\end{array}$ \\
\hline \multirow[t]{4}{*}{$\mathrm{Fe}$} & \multirow[t]{3}{*}{$\begin{array}{l}\text { Methanobacteria } \\
(7,97 \pm 0,45)\end{array}$} & \multirow[t]{3}{*}{$\begin{array}{l}\text { Methanobacteriales } \\
\quad(7,97 \pm 0,45)\end{array}$} & \multirow[t]{3}{*}{$\begin{array}{l}\text { Methanobacteriaceae } \\
(7,97 \pm 0,45)\end{array}$} & $\begin{array}{c}\text { Methanobacterium } \\
(0,10 \pm 0,06)\end{array}$ \\
\hline & & & & $\begin{array}{c}\text { Methanobrevibacter } \\
(7,79 \pm 0,40)\end{array}$ \\
\hline & & & & $\begin{array}{c}\text { Methanosphaera } \\
(0,08 \pm 0,04)\end{array}$ \\
\hline & $\begin{array}{c}\text { Methanomicrobia } \\
\left(0,70 \pm 0,08^{* *}\right)\end{array}$ & $\begin{array}{c}\text { Methanomicrobiales } \\
(0,70 \pm 0,08)\end{array}$ & $\begin{array}{c}\text { Methanomicrobiaceae } \\
(0,70 \pm 0,08)\end{array}$ & $\begin{array}{c}\text { Methanomicrobium } \\
(0,70 \pm 0,08)\end{array}$ \\
\hline \multirow[t]{4}{*}{$\mathrm{Cr}_{2} \mathrm{O}_{3}$} & \multirow[t]{3}{*}{$\begin{array}{c}\text { Methanobacteria } \\
\left(8,44 \pm 2,36^{*}\right)\end{array}$} & \multirow[t]{3}{*}{$\begin{array}{c}\text { Methanobacteriales } \\
(8,44 \pm 2,36)\end{array}$} & \multirow[t]{3}{*}{$\begin{array}{c}\text { Methanobacteriaceae } \\
\quad(8,44 \pm 2,36)\end{array}$} & $\begin{array}{c}\text { Methanobacterium } \\
(0,41 \pm 0,36)\end{array}$ \\
\hline & & & & $\begin{array}{c}\text { Methanobrevibacter } \\
(7,90 \pm 2,07)\end{array}$ \\
\hline & & & & $\begin{array}{c}\text { Methanosphaera } \\
(0,13 \pm 0,07)\end{array}$ \\
\hline & $\begin{array}{l}\text { Methanomicrobia } \\
\left(0,65 \pm 0,06^{* *}\right)\end{array}$ & $\begin{array}{c}\text { Methanomicrobiales } \\
(0,65 \pm 0,06)\end{array}$ & $\begin{array}{c}\text { Methanomicrobiaceae } \\
(0,65 \pm 0,06)\end{array}$ & $\begin{array}{c}\text { Methanomicrobium } \\
(0,65 \pm 0,06)\end{array}$ \\
\hline
\end{tabular}

$* \mathrm{p} \leq 0.05 ; * * \mathrm{p} \leq 0.01$ versus control versus control

\section{Result Discussion}

After analyzing the structure and composition of the microbial community in the contents of the rumen sampled for different diets, it was found that no significant differences were observed in the bacterial communities, with the exception of a slight shift in the Bacteroidetes/Firmicutes ratio, which is known to vary widely in individual animals. However, we observed numerical differences in abundance of some representatives. A decrease in the number of bacteria in the CR is possibly associated with the toxic effect of UFP additives on them; however, along with this, inhibition of methanogens in these groups was also noted [11]. In addition, the data obtained are contrary to the information obtained earlier on ferrum citrate [12]. The type of feed offered to ruminants, their ratio and presence of additional components in the diet affect rumen fermentation and, therefore, methane production. There is evidence of methane energy loss from 6 to $7 \%$ of total energy consumption when feed was fed at the maintenance level, and a decrease to $2-3 \%$ when giving concentrates against the background of a standard diet. It was found that a change in the diet for cattle led to a change in the nature of fermentation in the rumen and, 
as a consequence, the creation of a more hostile environment for methanogenic bacteria, in which the rate of passage increases, the $\mathrm{pH}$ of the content decreases and some populations of protozoa, mucosal cilia and methanogenic bacteria can be eliminated or suppressed [13, 14]. Similar effects were observed in our experiment.

Methanogens are a separate group of microorganisms that belong to the Archaea domain and the Euryarchaeota type [15]. In the rumen, methanogens use hydrogen and $\mathrm{CO} 2$ to produce $\mathrm{CH} 4$. Cultivated methanogens were assigned to seven species: Methanobrevibacter ruminantium, Methanobacterium formicicum, Methanobacterium bryantii, Methnaomicrobium mobile and Methanoculleus olentangyi [16]. With inclusion of $\mathrm{Fe}$ and $\mathrm{Cr} 2 \mathrm{O} 3$ UFP, a decrease in the abundance of the Methanobrevibacter, Methanobacterium, Methanosphaera and Methnaomicrobium species was noted relative to the control. The data obtained differ from the results obtained earlier in relation to various forms of ferrum [17].

\section{Conclusion}

Reducing the production of methane in the digestive processes of ruminants is a complex problem, however, adjusting the diets by introducing additional ingredients into them, namely, ultradispersed mineral preparations (Fe and Cr2O3 UFP) can have a positive effect on reducing the production of methane, which is important in the ecology of the climate.

\section{Acknowledgments}

This study was performed with the financial support from the Russian Science Foundation (Project No.20-16-00088).

\section{Conflict of Interest}

Authors declares that they have no conflict of interest.

\section{References}

1. J. L. Black, T.M. Davison, I. Box, Animals (Basel), 11(4), 951 (2021)

2. K. A. Beauchemin, E. M. Ungerfeld, R. J. Eckard, M. Wang, 14(S1), 2 (2020)

3. D. Olijhoek, P. Lund, Methane production by ruminants. Department of Animal science AU-Foulum. Aarhus University, Denmark (2017)

4. I. Karimov, K. Kondrashova, G. Duskaev, O. Kvan, E3S Web of Conferences, 143, 02034 (2020)

5. K. Logachev, I. Karimov, G. Duskaev, A. Frolov, S. Tulebaev, O. Zav'yalov, Asian Journal of Animal Sciences, 9(5), 248 (2015)

6. C. Martin, D.P. Morgavi, M. Doreau, Animal, 4(3), 351 (2009)

7. Y.Q. Guo, J.X. Liu, Y. Lu, W.Y. Zhu, S.E. Denman, Lett Appl Microbial, 47(5), 421 (2008)

8. M. Ramin, P. Fant, P. Huhtanen, J. Dairy Sci., 104(5), 5617 (2021)

9. J. C. Ku-Vera, O. A. Castelán-Ortega, F. A. Galindo-Maldonado, J. Arango, N. Chirinda, R. Jiménez-Ocampo, S. S. Valencia-Salazar, E. J. Flores-Santiago, M. D. Montoya-Flores, I. C. Molina-Botero, A. T. Piñeiro-Vázquez et. al, Animal, 14(S3), $453(2020)$ 
10. P. K. Malik, S. Trivedi, A. Mohapatra, A. P. Kolte, V. Sejian, R. Bhatta, H. Rahman, PLoS One, 16(8), e0256048 (2021)

11. M. Popova, J. Guyader, M. Silberberg, A. R. Seradj, C. Saro, A. Bernard, C. Gérard, C. Martin, D. P. Morgavi, Appl Environ Microbiol, 85(4), e02657 (2019)

12. B. A. Clemmons, L. G. Schneider, E. A. Melchior, A. K. Lindholm-Perry, K. E. Hales, J. E. Wells, H. C. Freetly, S. L. Hansen, M. E. Drewnoski, S. J. Hartman, P. R. Myer Access Microbiol, 3(1), acmi000180 (2020)

13. F. Dehareng, C. Delfosse, E. Froidmont, H. Soyeurt, C. Martin et al, Animal, 6(10), 1694 (2012)

14. P. J. Van Soest, Nutritional Ecology of the Rumi-nant, 40 (1982)

15. A. K. Almeida, R. S. Hegarty, A. Cowie, Anim Nutr., 7(4), 1219 (2021)

16. P. H. Janssen, M. Kirs, Applied and Environmental Microbiology, 74(12), 3619 (2008)

17. H. Wu, Q. Meng, Z. Yu, Bioresour Technol., 211, 603 (2016) 